\title{
Effects of Cu diffusion-doping on structural, optical, and magnetic properties of ZnO nanorod arrays grown by vapor phase transport method
}

Cite as: J. Appl. Phys. 111, 013903 (2012); https://doi.org/10.1063/1.3673861

Submitted: 20 September 2011 . Accepted: 05 December 2011 . Published Online: 03 January 2012

S. Yılmaz, E. McGlynn, E. Bacaksız, Ş. Özcan, D. Byrne, M. O. Henry, and R. K. Chellappan

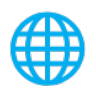

\section{ARTICLES YOU MAY BE INTERESTED IN}

A comprehensive review of $\mathrm{ZnO}$ materials and devices

Journal of Applied Physics 98, 041301 (2005); https://doi.org/10.1063/1.1992666

Green luminescence from $\mathrm{Cu}$-doped $\mathrm{ZnO}$ nanorods: Role of $\mathrm{Zn}$ vacancies and negative thermal quenching

Applied Physics Letters 102, 111106 (2013); https://doi.org/10.1063/1.4798240

Defects in ZnO

Journal of Applied Physics 106, 071101 (2009); https://doi.org/10.1063/1.3216464

Journal of Applied Physics
SPECIAL TOPIC:

Antiferromagnetic Spintronics 


\title{
Effects of $\mathrm{Cu}$ diffusion-doping on structural, optical, and magnetic properties of $\mathrm{ZnO}$ nanorod arrays grown by vapor phase transport method
}

\author{
S. Yilmaz, ${ }^{1,2, a)}$ E. McGlynn, ${ }^{1}$ E. Bacaksız, ${ }^{2}$ S. Özcan, ${ }^{3}$ D. Byrne,${ }^{1}$ M. O. Henry, ${ }^{1}$ and \\ R. K. Chellappan ${ }^{4}$ \\ ${ }^{1}$ School of Physical Sciences and National Centre for Plasma Science and Technology, Dublin City University, \\ Glasnevin, Dublin 9, Ireland \\ ${ }^{2}$ Department of Physics, Faculty of Sciences, Karadeniz Technical University, 61080 Trabzon, Turkey \\ ${ }^{3}$ SNTG Laboratory, Physics Engineering Department, Hacettepe University, Beytepe, 06800 Ankara, Turkey \\ ${ }^{4}$ School of Physical Sciences and National Centre for Sensor Research, Dublin City University, Glasnevin, \\ Dublin 9, Ireland
}

(Received 20 September 2011; accepted 5 December 2011; published online 3 January 2012)

Well-aligned $\mathrm{ZnO}$ nanorods were prepared by the vapor phase transport method on Si covered with a $\mathrm{ZnO}$ buffer layer. After the nanostructure growth, $\mathrm{Cu}$ was doped into the $\mathrm{ZnO}$ nanorods by diffusion at three different temperatures and for different times. Undoped and $\mathrm{Cu}$ diffusion-doped $\mathrm{ZnO}$ samples are highly textured, with the $\mathrm{c}$ axis of the wurtzite structure along the growth direction. The incorporation of $\mathrm{Cu}$ caused some slight changes in the nanorod alignment, although the wurtzite crystal structure was maintained. X-ray photoelectron spectroscopy measurements revealed that $\mathrm{Cu}$ ions were in a divalent state and substituted for the $\mathrm{Zn}^{2+}$ ions of the $\mathrm{ZnO}$ matrix. Photoluminescence results at $10 \mathrm{~K}$ indicate that the incorporation of copper leads to a relative increase of $\mathrm{Cu}$-related structured green band deep level intensity. Magnetic measurements revealed that both undoped and $\mathrm{Cu}$ diffusion-doped $\mathrm{ZnO}$ samples exhibited room temperature ferromagnetism. It was also found that bound magnetic polarons play an important role in the appearance of room temperature ferromagnetism in $\mathrm{Cu}$ diffusion-doped $\mathrm{ZnO}$ nanorods. (C) 2012 American Institute of Physics. [doi:10.1063/1.3673861]

\section{INTRODUCTION}

One-dimensional materials including nanowires, nanorods, nanobelts, and nanotubes have drawn much attention due to their importance in basic scientific research and potential technological applications in nanodevices such as nanowire field-effect-transistors, nanolasers, and nanogenerator. ${ }^{1-3}$ Among the already known semiconductor nanomaterials, $\mathrm{ZnO}$ has attracted increasing interest due to its potential applications in many areas such as field-emission displays, solar cells, and gas sensors. ${ }^{4} \mathrm{ZnO}$ has also emerged as a promising material for dilute magnetic semiconductors (DMSs). ${ }^{5}$ DMS are formed by partial replacement of cations in a nonmagnetic semiconductor by $3 \mathrm{~d}$ transition metal ions (e.g., Co, Mn, Fe, $\mathrm{Cr}, \mathrm{Ni}$, and $\mathrm{Cu}$ ) and are currently attractive materials for semiconductor spintronic applications. ${ }^{6}$ The field of semiconductor spintronics has the goal of utilizing the spin as well as the charge of the carriers in a new generation of devices such as spin-valve transistors, spin light-emitting diodes, and logic devices. ${ }^{7-9}$ To realize these devices, it is necessary to develop semiconducting materials that show ferromagnetism at room temperature. In 2000, Dietl et al. ${ }^{10}$ predicted theoretically that $\mathrm{Mn}$-doped $\mathrm{ZnO}$ and $\mathrm{GaN}$ would be ferromagnetic at room temperature and would, therefore, be suitable for applications in spintronics. Following this direction, using ab-initio calculations based on the local density approximation, Sato and Katayama-Yoshida ${ }^{11}$ theoretically demonstrated that V-, Fe-,

\footnotetext{
a) Author to whom correspondence should be addressed. Electronic mail: s_yilmaz@ktu.edu.tr.
}

Co-, Ni-, and $\mathrm{Cr}$-doped $\mathrm{ZnO}$ should show ferromagnetic ordering at and above room temperature. After these theoretical studies, Ueda et al. ${ }^{12}$ experimentally reported ferromagnetic behavior with a Curie temperature higher than room temperature for Co-doped $\mathrm{ZnO}$ films grown by pulsed laser deposition, however Jin et al. ${ }^{13}$ observed no indication of ferromagnetism in films grown on sapphire (0001) by laser molecular beam epitaxy. Early studies explained ferromagnetism in $\mathrm{ZnO}$ in terms of a free carrier mediated mechanism resulting from ferromagnetic behavior in oxide based DMS. ${ }^{11}$ However, more recent studies proposed that defects like oxygen vacancies are giving rise to ferromagnetic ordering. ${ }^{14}$ These results are indicative of the broader state of affairs with regard to $\mathrm{ZnO}$, i.e., that there is no consensus on ferromagnetic behavior and its origin for $\mathrm{ZnO}$-based materials.

Recently, there has been a lot of interest in studying transition metal-doped $\mathrm{ZnO}$ nanostructures. ${ }^{15-17}$ Among these reports, $\mathrm{Cu}$-doped $\mathrm{ZnO}$ studies have aroused a lot of interest because the substitution of $\mathrm{Cu}$ at the sites of $\mathrm{Zn}$ atoms with appropriate doping content supports a ferromagnetic ground state which was proposed by several first principles calculations. ${ }^{18-20}$ These theoretical predictions were later supported by experimental observations of room temperature ferromagnetism in $\mathrm{Cu}$-doped $\mathrm{ZnO}$ thin films. ${ }^{21-23}$ However, there are few reports on one-dimensional $\mathrm{Cu}$-doped $\mathrm{ZnO}$ nanostructures, especially well-aligned nanorod arrays. ${ }^{15,24}$

There are various methods to fabricate one-dimensional transition metal-doped $\mathrm{ZnO}$ materials. These techniques include chemical vapor deposition, ${ }^{25}$ hydrothermal method, ${ }^{26}$ thermal evaporation, ${ }^{27}$ ion implantation, ${ }^{28}$ and vapor phase 
transport method (VPT). ${ }^{29}$ Among these methods, VPT method is widely used because of relatively simple apparatus requirements and has been employed to fabricate various nanostructures of $\mathrm{ZnO} .^{30,31}$ Furthermore, there is much less research on the use of VPT method for the growth of onedimensional transition metal-doped $\mathrm{ZnO}$ materials in the literature and it is our intention to undertake a novel and necessary study of the use and potential of this growth method to grow ZnO-based DMS. In this communication, we present data on well-aligned $\mathrm{ZnO}$ nanorod arrays synthesized via VPT on $\mathrm{ZnO}$ buffer layer coated $\mathrm{Si}$ substrates and specifically we study the effects of different annealing temperatures and times on $\mathrm{Cu}$ diffusion-doped samples using $\mathrm{x}$-ray diffraction (XRD), scanning electron microscopy (SEM), X-ray photoelectron spectroscopy (XPS), photoluminescence (PL), and magnetic measurements. We discuss the relationship between the optical and magnetic properties with a view to explaining the origin of observed room temperature ferromagnetism in our $\mathrm{Cu}$ diffusion-doped $\mathrm{ZnO}$ nanorod samples.

\section{EXPERIMENTAL DETAILS}

Well aligned $\mathrm{ZnO}$ nanorods were grown on silicon substrates using a three step approach consisting of an initial seeding of substrates and followed by a chemical bath deposition (CBD) and finally VPT nanorod growth. Full details of the growth method may be found in Ref. 32 .

n-type $\mathrm{Si}$ (100) wafers (thickness $508 \pm 20 \mu \mathrm{m}$, resistivity $5-9 \Omega \mathrm{cm}$ ) were cut into $1 \times 1.5 \mathrm{~cm}^{2}$ pieces as substrates, cleaned ultrasonically in sequence with acetone, ethanol, and then blown dry with a nitrogen flow. To grow the $\mathrm{ZnO}$ seed layer, zinc acetate dihydrate $\left(\mathrm{Zn}\left(\mathrm{OOCCH}_{3}\right)_{2} \cdot 2 \mathrm{H}_{2} \mathrm{O}\right)$ was dissolved in the absolute ethanol with concentration of $5 \mathrm{mM}$ and this solution was coated onto $\mathrm{Si}$ wafers by drop coating with a volume per area of $3.5 \mu \mathrm{L} / \mathrm{cm}^{2}$. The substrates were rinsed with fresh ethanol after drop coating after $20 \mathrm{~s}$ and then dried with a nitrogen stream. This procedure was repeated five times for each sample and then the samples were annealed at $350^{\circ} \mathrm{C}$ for $30 \mathrm{~min}$ in ambient air to produce the initial textured $\mathrm{ZnO}$ seed layer which provides nucleation sites for subsequent steps and also provides good alignment to the $\mathrm{ZnO}$ nanorods to be grown by the CBD method, as described in Refs. 32 and 33.

In the CBD process, $25 \mathrm{mM}$ zinc nitrate hexahydrate $\left(\mathrm{Zn}\left(\mathrm{NO}_{3}\right)_{2} \cdot 6 \mathrm{H}_{2} \mathrm{O}\right)$ was dissolved in deionized water $(40 \mathrm{ml})$ and $25 \mathrm{mM}$ hexamethylenetetramine $\left(\mathrm{C}_{6} \mathrm{H}_{12} \mathrm{~N}_{4}\right)$ was added to the solution to induce the formation of $\mathrm{ZnO}$ nanorods. ${ }^{34} \mathrm{ZnO}$ seeded substrates were immersed vertically into the aqueous solution and heated at a constant temperature of $80^{\circ} \mathrm{C}$ using water baths for $40 \mathrm{~min}$, with stirring. After deposition, samples were taken from the solution, ultrasonically cleaned with deionized water for $5 \mathrm{~min}$ to remove white loosely adherent powder precipitates, rinsed with ethanol, and dried with nitrogen.

For the VPT growth stage, $0.06 \mathrm{~g}$ of $\mathrm{ZnO}$ and graphite powders were thoroughly mixed together and placed in the middle of an alumina boat. Substrates which were covered $\mathrm{ZnO}$ buffer layers (seed layer plus $\mathrm{CBD}$ ) were placed directly above the source material with the growth surface facing the powder. The boat was loaded in the central part of a tube fur- nace. The growth was carried out at $925^{\circ} \mathrm{C}$ with a $90 \mathrm{sccm}$ flow of argon for $1 \mathrm{~h}$. The furnace was then cooled down to room temperature and the samples were taken out.

$\mathrm{Cu}$ metal with purity of 99.98 at. \% was evaporated on the vertically aligned $\mathrm{ZnO}$ nanorods by e-beam evaporation (Leybold Univex 350). The system pressure during deposition was $\sim 6 \times 10^{-6}$ Torr. The amount of copper deposited onto $\mathrm{ZnO}$ nanorods was controlled by a quartz crystal thickness monitor (Inficon XTM/2) and equivalent thickness of the $\mathrm{Cu}$ layer was $\sim 5 \mathrm{~nm}$. After the $\mathrm{Cu}$ deposition, the samples were annealed in a quartz tube at various temperatures ranging from $500^{\circ} \mathrm{C}$ to $700^{\circ} \mathrm{C}$ for $8 \mathrm{~h}$ and a fixed temperatures of $700^{\circ} \mathrm{C}$ for different times ranging from $8 \mathrm{~h}$ to $24 \mathrm{~h}$ in a vacuum of $\sim 10^{-2}$ Torr.

The crystal structure of the samples was investigated using a Bruker AXS D8 advance texture diffractometer with $\mathrm{CuK}_{\alpha}$ radiation, operated at a voltage of $40 \mathrm{kV}$, and a current of $40 \mathrm{~mA}$, over the range $2 \theta=20^{\circ}-60^{\circ}$ with a step of $0.01^{\circ}$ at room temperature. The crystal quality was further studied by $\mathrm{x}$-ray rocking curve (XRC) measurements of the $\mathrm{ZnO}$ (002) reflection. The surface morphology and bulk composition were studied with a Zeiss EVOLS 15 SEM equipped with energy dispersive x-ray spectroscopy (EDS). An acceleration voltage of $20 \mathrm{kV}$ was used in all cases for these studies. The chemical composition and bonding at the surface (sampling depth $\sim 5 \mathrm{~nm}$ ) were characterized by using XPS with Al K $\alpha$ radiation $(1486.6 \mathrm{eV})$. The kinetic energy of the photo emitted electrons from the surface was measured in an electron energy analyzer, operated in constant pass energy mode under ultra high vacuum $\left(\sim 10^{-10}\right.$ mbar). Due to charging effects, the $\mathrm{C}$ $1 \mathrm{~s}$ photoelectron peak at $285.0 \mathrm{eV}$ was consistently used as a reference for the charge-correction of binding energies of core level peaks. PL measurements were performed at $10 \mathrm{~K}$, using a SPEX 1704 monochromator, with a closed cycle cryostat (Janis SHI-950-5). PL spectra were excited with the $325 \mathrm{~nm}$ line of a $\mathrm{He}-\mathrm{Cd}$ laser operating at $200 \mathrm{~mW}$. Magnetization measurements of the samples as a function of magnetic field and temperature were carried out using a quantum design physical property measurement system (PPMS) system with a vibrating sample magnetometer module.

\section{RESULTS AND DISCUSSION}

Figs. 1(a)-1(d) shows the powder 2 $\theta-\omega$ XRD patterns of undoped and $\mathrm{Cu}$ diffused $\mathrm{ZnO}$ nanorods annealed at a constant temperature of $700^{\circ} \mathrm{C}$ for $8 \mathrm{~h}, 16 \mathrm{~h}$, and $24 \mathrm{~h}$ in vacuum atmosphere, respectively. The only peak related to $\mathrm{ZnO}$ is the (002) peak and these XRD results suggest that all the samples have the hexagonal wurtzite structure with a highly c-axis preferred orientation perpendicular to the substrate, which is consistent with the SEM results shown later. No traces of copper and its oxides such as $\mathrm{CuO}, \mathrm{Cu}_{2} \mathrm{O}$ were detected in our samples within the detection limit of the XRD measurements. The $\mathrm{ZnO}$ (002) reflection peak of undoped $\mathrm{ZnO}$ nanorods is located at $34.43^{\circ}$ which corresponds to a c-lattice parameter value of $5.21 \AA$, consistent with the value for bulk material within the accuracy of our experimental system. ${ }^{35}$ Compared with the undoped sample, the c-lattice constant values of $\mathrm{ZnO}: \mathrm{Cu}$ samples have not changed significantly, probably due to the very similar ionic radii of $\mathrm{Zn}^{2+}(0.74 \AA)$ and $\mathrm{Cu}^{2+}$ 


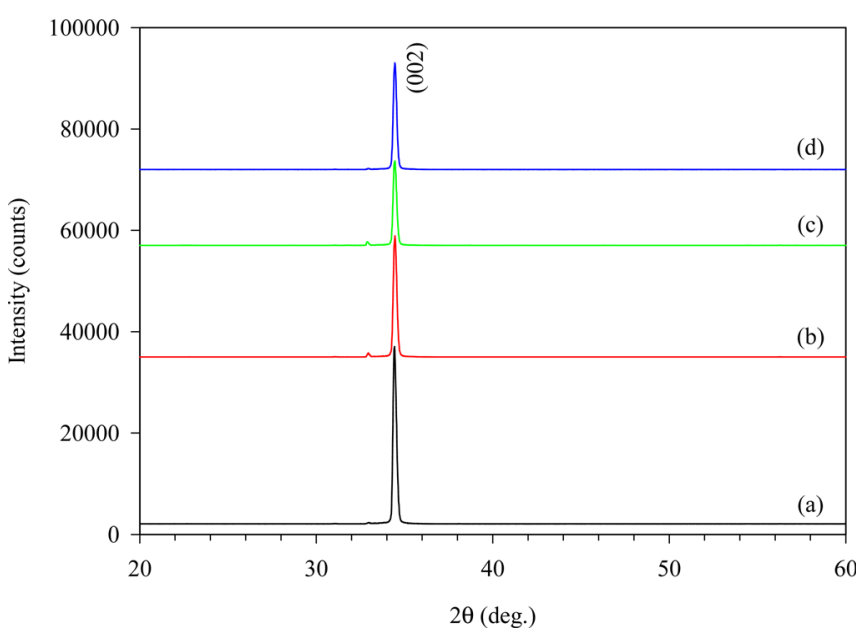

FIG. 1. (Color online) XRD patterns of undoped $\mathrm{ZnO}$ (a), and $\mathrm{Cu}$ diffusiondoped $\mathrm{ZnO}$ nanorods annealed at $700{ }^{\circ} \mathrm{C}$ for $8 \mathrm{~h}(\mathrm{~b}), 16 \mathrm{~h}(\mathrm{c})$, and $24 \mathrm{~h}(\mathrm{~d})$.

$(0.73 \AA)$. The weak peak at $\sim 33^{\circ}$ is due to the nominally forbidden $\mathrm{Si}(002)$ reflection which is allowed by double diffraction effects. ${ }^{36}$

To further investigate the crystallinity and alignment of the one-dimensional $\mathrm{ZnO}$ nanorods, XRC measurements were carried out. Figs. 2(a)-2(d) presents the XRC data for the $\mathrm{ZnO}$ (002) diffraction peaks obtained from the same samples shown in Fig. 1 (and in the same order). The full width at half-maximum (FWHM) value of the undoped $\mathrm{ZnO}$ sample is $3.36^{\circ}$, which indicates excellent alignment of the nanorods perpendicular to the substrate surface. A very similar value of XRC FWHM was reported by Wang et al. ${ }^{37}$ for $\mathrm{Cu}-$ doped $\mathrm{ZnO}$ films synthesized with magnetron sputtering. On the other hand, Yanmei et al. ${ }^{38}$ found a larger FWHM value of $10.4^{\circ}$ for undoped $\mathrm{ZnO}$ in hydrothermal grown $\mathrm{Ni}: \mathrm{ZnO}$ nanorods. After $\mathrm{Cu}$ evaporation and subsequent annealing and diffusion, the intensity of the $\mathrm{ZnO}$ (002) peak compared to the undoped $\mathrm{ZnO}$ firstly decreases slightly and then increases slightly for the sample annealed at $700{ }^{\circ} \mathrm{C}$ for $24 \mathrm{~h}$. This change in (002) intensity is likely to be related to changes in the FWHM values which firstly increases to $5.08^{\circ}$

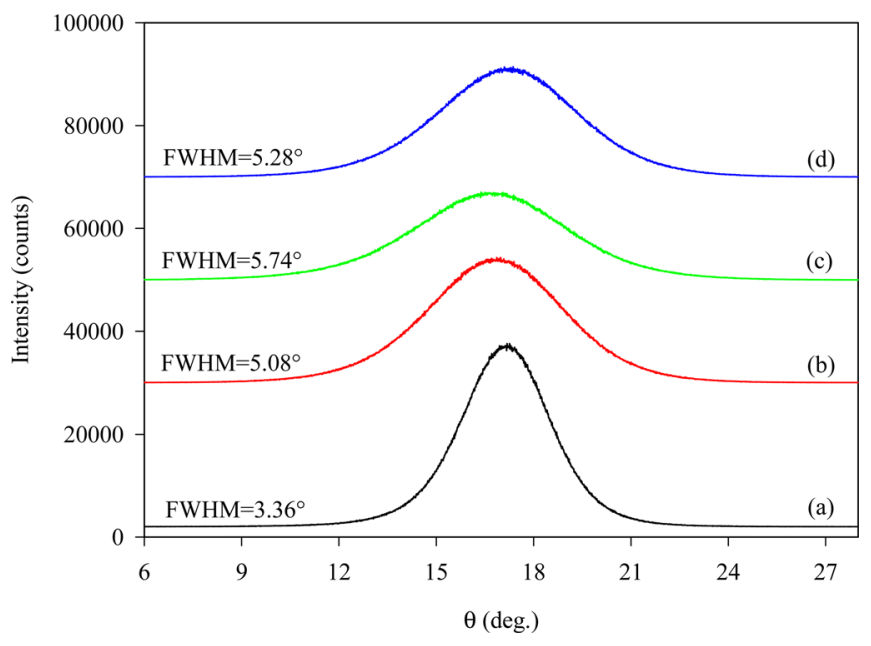

FIG. 2. (Color online) The Rocking curves of undoped $\mathrm{ZnO}$ (a), and $\mathrm{Cu}$ diffusion-doped $\mathrm{ZnO}$ nanorods annealed at $700{ }^{\circ} \mathrm{C}$ for $8 \mathrm{~h}(\mathrm{~b}), 16 \mathrm{~h} \mathrm{(c)}$, and $24 \mathrm{~h}(\mathrm{~d})$. and $5.74^{\circ}$ for the samples annealed $700^{\circ} \mathrm{C}$ for 8 and $16 \mathrm{~h}$, respectively, and then decreases to $5.28^{\circ}$ (Ref. 39).

The surface morphology of nanorods on $\mathrm{ZnO}$ buffer layer coated Si substrates was investigated by SEM. Figs. 3(a)-3(d) shows typical SEM images of $\mathrm{ZnO}$ nanorods for the sample diffusion-doped with $\mathrm{Cu}$ and annealed at $700^{\circ} \mathrm{C}$ for $16 \mathrm{~h}$. Fig. 3(a) and 3(b) illustrate top view and $45^{\circ}$ tilted view images of the $\mathrm{ZnO}: \mathrm{Cu}$ nanorod arrays, respectively, implying that $\mathrm{ZnO}: \mathrm{Cu}$ samples grew uniformly over a large area. The magnified image of the top view is presented in the inset of Fig. 3(a), showing that $\mathrm{ZnO}: \mathrm{Cu}$ nanorods have a well-defined hexagonal prism shape with a diameter of $\sim 100 \mathrm{~nm}$. Figs. 3(c) and $3(\mathrm{~d})$ display a $45^{\circ}$ tilted view image obtained from the edge of the sample and cross-section image of $\mathrm{ZnO}: \mathrm{Cu}$ nanorod arrays, respectively, showing that all the $\mathrm{ZnO}$ nanorods grow predominantly vertical to the $\mathrm{ZnO}$ buffer layer coated $\mathrm{Si}$ substrates, in support of XRD and XRC data, and that almost all nanorods have similar lengths, typically up to $4.0 \mu \mathrm{m}$ long.

Chemical composition and elemental homogeneity of the samples were determined by EDS. Fig. 4(a) shows the SEM image obtained from $\mathrm{ZnO}: \mathrm{Cu}$ nanorod sample annealed at $700{ }^{\circ} \mathrm{C}$ for $16 \mathrm{~h}$. Figs. 4(b)-4(d) indicates EDS mapping of $\mathrm{Zn}, \mathrm{O}$, and $\mathrm{Cu}$ elements, respectively. As can be seen in Figs. 4(b)-4(d), Zn, O, and $\mathrm{Cu}$ elements indicate a uniform distribution in the $\mathrm{ZnO}: \mathrm{Cu}$ sample annealed at $700{ }^{\circ} \mathrm{C}$ for $16 \mathrm{~h}$. In addition, it was found that the atomic ratio of $\mathrm{Cu} /$ $\mathrm{Zn}+\mathrm{O}$ for $\mathrm{ZnO}: \mathrm{Cu}$ annealed at $600^{\circ} \mathrm{C}$ for $8 \mathrm{~h}$ was $\sim 0.64$ at. $\%$, however, the atomic ratios of $\mathrm{Cu} / \mathrm{Zn}+\mathrm{O}$ of all the other $\mathrm{ZnO}: \mathrm{Cu}$ samples had the same value of $\sim 1$ at. $\%$.

The incorporation of $\mathrm{Cu}$ ions into the $\mathrm{ZnO}$ lattice and their valence states were characterized by XPS measurements. Fig. 5(a) shows the full-range XPS survey spectrum for undoped $\mathrm{ZnO}$ and $\mathrm{ZnO}: \mathrm{Cu}$ nanorods annealed at $700{ }^{\circ} \mathrm{C}$ for $24 \mathrm{~h}$ and only peaks corresponding to $\mathrm{Zn}, \mathrm{C}, \mathrm{O}$, and $\mathrm{Cu}$ are identified. Fig. 5(b) illustrates $\mathrm{Cu} 2 \mathrm{p}$ core-level XPS spectra of $\mathrm{ZnO}: \mathrm{Cu}$ sample annealed at $700^{\circ} \mathrm{C}$ for $24 \mathrm{~h}$ in vacuum. As can be seen from Fig. 5(b), the $2 \mathrm{p}$ level is split into a doublet with an energy separation due to the spin-orbit interaction. ${ }^{40}$ $\mathrm{Cu} 2 \mathrm{p} 3 / 2$ and $2 \mathrm{p} 1 / 2$ core levels of the sample were fitted with Gaussian functions and centered at 933.7 and $953.5 \mathrm{eV}$, respectively, implying that $\mathrm{Cu}$ is in a divalent valence state, which is good agreement with the other studies in the literature. ${ }^{41,42}$ Furthermore, a satellite peak is observed at binding energies in the range of $940-945 \mathrm{eV} . \mathrm{CuO}\left(\mathrm{Cu}^{2+}\right)$ differs from metallic copper $\left(\mathrm{Cu}^{0}\right)$ and $\mathrm{Cu}_{2} \mathrm{O}\left(\mathrm{Cu}^{1+}\right)$ because $\mathrm{Cu}^{2+}$ is known to have $\mathrm{Cu} 2 \mathrm{p}$ satellite peaks at higher binding energy associated with the existence of $\mathrm{Cu} 3 \mathrm{~d}$ hole states $\left(\mathrm{Cu} 3 \mathrm{~d}^{9}\right)$. However, $\mathrm{Cu}^{1+}$ and $\mathrm{Cu}^{0}$ do not exhibit any satellite peaks since the $3 \mathrm{~d}$ band of $\mathrm{Cu}_{2} \mathrm{O}$ is filled $\left(\mathrm{Cu} 3 \mathrm{~d}^{10}\right)$ and the $4 \mathrm{~s}$ band is unoccupied. ${ }^{43,44}$ Thus, based on all the discussions above, we can conclude that $\mathrm{Cu}$ is in a divalent valence state.

In order to investigate the influence of $\mathrm{Cu}$ diffusion doping on optical emission and defect formation, PL spectra of all the samples were measured at $10 \mathrm{~K}$. Figs. 6(a)-6(f) shows $\mathrm{PL}$ spectra of undoped and $\mathrm{Cu}$ diffusion-doped $\mathrm{ZnO}$ nanorods annealed at $500{ }^{\circ} \mathrm{C}, 600^{\circ} \mathrm{C}$, and $700^{\circ} \mathrm{C}$ for $8 \mathrm{~h}$ and at $700{ }^{\circ} \mathrm{C}$ for $16 \mathrm{~h}$ and $24 \mathrm{~h}$, respectively (all spectra normalized to the near band edge (NBE) peak emission). The dominant UV peak seen in all the samples is located at $\sim 3.367 \mathrm{eV}$ and 


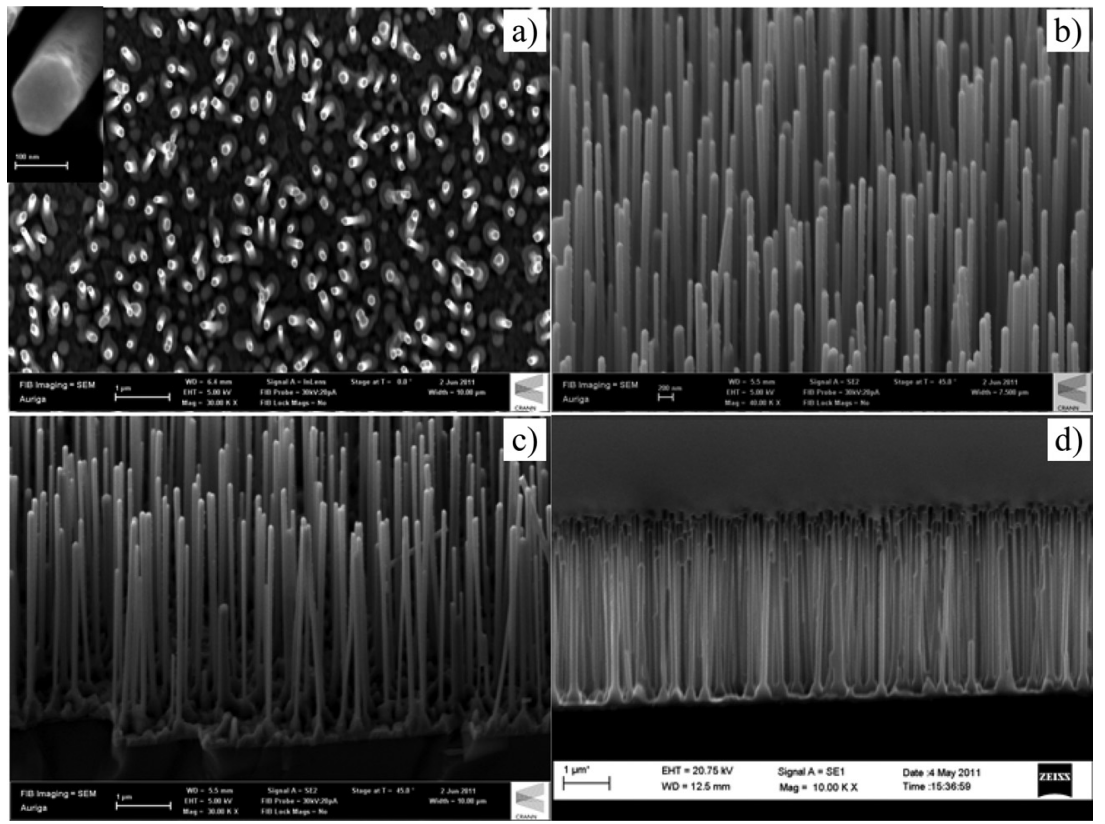

FIG. 3. SEM images of (a) Top view, (b) $45^{\circ}$ tilted view, (c) $45^{\circ}$ tilted view obtained from edge of sample, and (d) cross-section of $\mathrm{ZnO}: \mathrm{Cu}$ nanorods annealed at $700{ }^{\circ} \mathrm{C}$ for $16 \mathrm{~h}$ is ascribed to the NBE emission due to excitons bound to donors $\left(\mathrm{D}^{0} \mathrm{X}\right.$, members of the so-called I line series). ${ }^{45}$ The energies of these peaks are identical within about $4 \mathrm{meV}$ for all samples, indicating that the dominant donor bound exciton emission energy is not significantly affected by the $\mathrm{Cu}$ incorporation. This $\mathrm{D}^{0} \mathrm{X}$ emission is observed at a constant energy below the band gap and thus indicates that the band gaps at low temperatures in all samples are identical. The inset of the Fig. 6 shows PL data of $\mathrm{ZnO}: \mathrm{Cu}$ nanorod arrays annealed at $500{ }^{\circ} \mathrm{C}$ for $8 \mathrm{~h}$ measured at $10 \mathrm{~K}$ in the range of $366-371 \mathrm{~nm}$, scanned with a step size of $0.04 \mathrm{~nm}$. As can be seen from the inset, dominant lines located at energies $3.357 \mathrm{eV}$ and $3.361 \mathrm{eV}$ result from the neutral donor bound excitons of $\mathrm{I}_{9}$ and $\mathrm{I}_{6}$, which are ascribed to $\mathrm{Al}$ and In donors, respectively. The content of In may come from source of powder used in our VPT system. The origin of Al contamination may be due to both source of powder and alumina boat used to evaporate the powder mixture. Various other higher energy bound exciton lines are seen due to other impurities and also to excited states of neutral donor bound excitons and ionized donor bound excitons and the free exciton emission positioned at $>3.375 \mathrm{eV}$ can be seen in the higher photon energy region of the spectrum. ${ }^{45}$

The deep level visible emission (DLE) region which is in the range of $430-650 \mathrm{~nm}$ is usually attributed (depending on the details of its shape and temperature dependence) to intrinsic defects such as zinc vacancy $\left(\mathrm{V}_{\mathrm{Zn}}\right)$, interstitial zinc $\left(\mathrm{Zn}_{\mathrm{i}}\right)$, oxygen vacancy $\left(\mathrm{V}_{\mathrm{o}}\right)$ and oxygen interstitial $\left(\mathrm{O}_{\mathrm{i}}\right)$ (for the case of the unstructured green band), as well as extrinsic impurities, such as substitutional $\mathrm{Cu}$ (for the structured green band). ${ }^{46,47}$ The structured green luminescence band was clearly observed in our samples. The energy spacing between two adjacent lines in the structure is almost $72 \mathrm{meV}$ and can be attributed to the LO phonon replicas. ${ }^{48}$ As illustrated in Fig. 6, Cu-diffused $\mathrm{ZnO}$ nanorods display this structured visible luminescence band which increases gradually in relative intensity with both annealing temperature and time indicating that $\mathrm{Cu}$ atoms have substituted into $\mathrm{ZnO}$ lattice sites. ${ }^{49}$ There is likely to also be

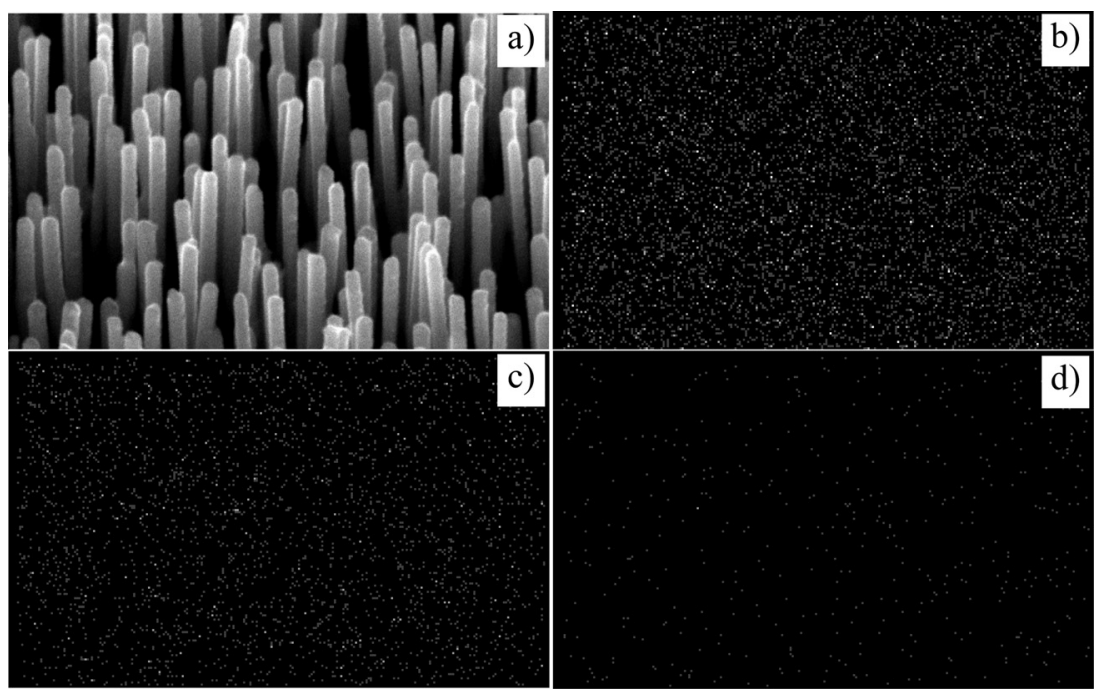

FIG. 4. (a) A SEM image and EDS mapping of (b) Zn, (c) $\mathrm{O}$, and (d) $\mathrm{Cu}$ elements of $\mathrm{ZnO}: \mathrm{Cu}$ nanorod sample annealed at $700{ }^{\circ} \mathrm{C}$ for $16 \mathrm{~h}$. 

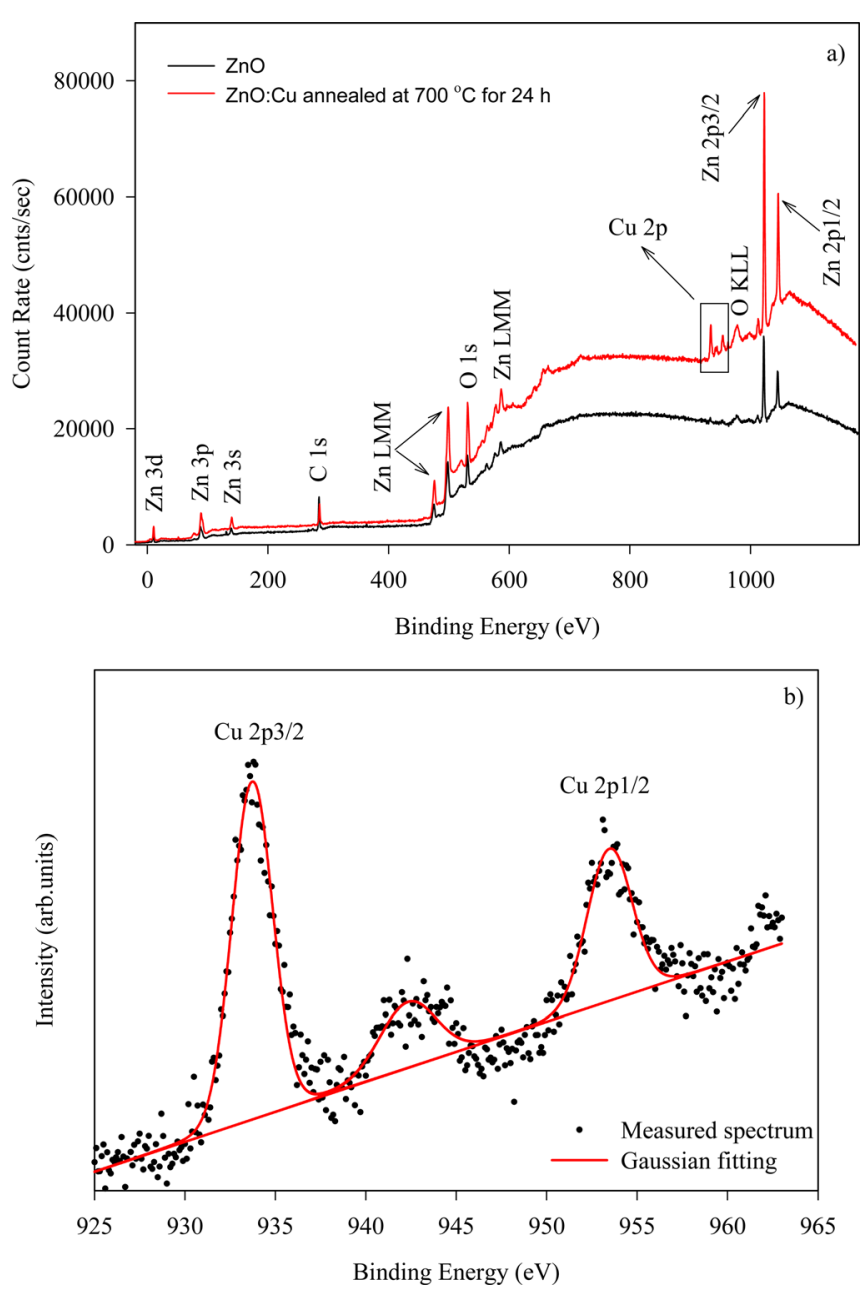

FIG. 5. (Color online) (a) XPS survey spectra of undoped and Cu diffusiondoped $\mathrm{ZnO}$ nanorod array annealed at $700^{\circ} \mathrm{C}$ for $24 \mathrm{~h}$, (b) shows binding energy spectrum of $\mathrm{Cu} 2 \mathrm{p}$ and Gaussian fitting.

simultaneous creation of point defects due to the vacuum annealing (to create $\mathrm{V}_{\mathrm{o}}$ ) and/or effects of $\mathrm{Cu}$ incorporation into $\mathrm{Zn}$ sites and hence there may be some complexing of $\mathrm{Cu}$ with native defects. ${ }^{50}$ In principle, the creation of $\mathrm{V}_{\mathrm{o}}$ defects should also lead to an increase of the unstructured green band but this is probably masked in our samples by the strong $\mathrm{Cu}$-related structured green band in the same spectral region.

The electrical conductivity properties of the film are also of relevance to analyses of the present type. The present samples are in the form of nanorods and thus do not form a continuous conducting film (noting also that the underlying buffer layer is quite thin and with a small grain size and thus will not show significant conductivity). The nanorod morphology means that measuring the conducting properties of individual nanorods is quite challenging. However, the presence of a range of I-line defects associated with donor bound excitons in the low temperature PL spectra of the samples indicates that these samples display background n-type conductivity in the nominally undoped condition, in line with the overwhelming majority of literature reports for nominally undoped $\mathrm{ZnO}$ material. Nominally, undoped $\mathrm{ZnO}$ nanorod samples are known from the literature to have carrier densities and mobilities of the order of $10^{17} \mathrm{~cm}^{-3}$ and $10 \mathrm{~cm}^{2} \mathrm{~V}^{-1} \mathrm{~s}^{-1}$, respectively, ${ }^{51}$ and we feel that our nominally undoped samples, of similar crystalline quality

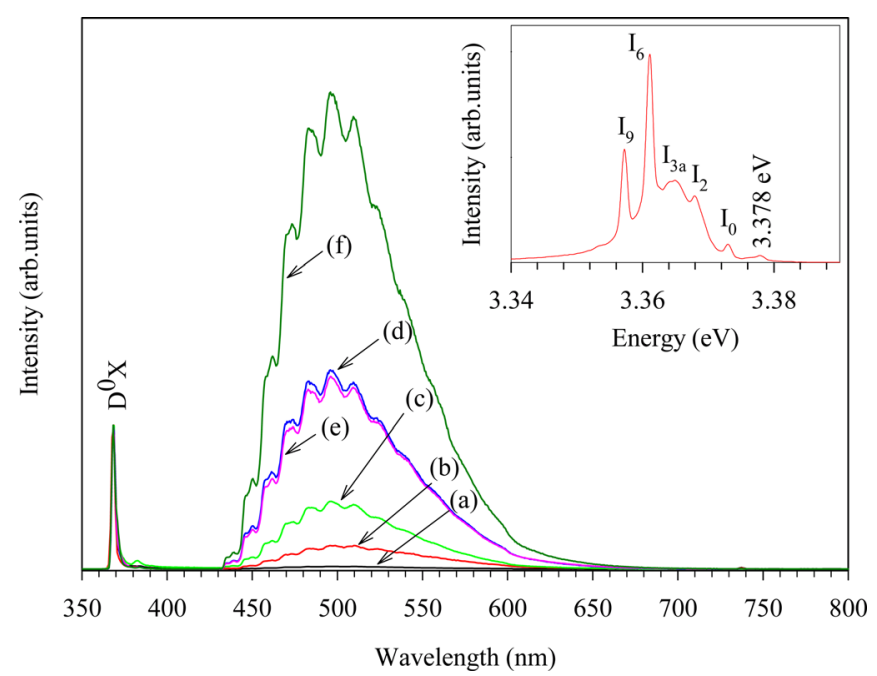

FIG. 6. (Color online) Low temperature PL spectra of undoped $\mathrm{ZnO}$ (a) and $\mathrm{Cu}$ diffusion-doped $\mathrm{ZnO}$ nanorods annealed at $500^{\circ} \mathrm{C}$ for $8 \mathrm{~h}(\mathrm{~b}), 600^{\circ} \mathrm{C}$ for $8 \mathrm{~h} \mathrm{(c),} 700^{\circ} \mathrm{C}$ for $8 \mathrm{~h} \mathrm{(d),} 700^{\circ} \mathrm{C}$ for $16 \mathrm{~h}$ (e), and $700^{\circ} \mathrm{C}$ for $24 \mathrm{~h}$ (f).

and grown at similar temperatures, would likely display similar electrical properties. Doping with $\mathrm{Cu}$, which can act as a deep acceptor, ${ }^{49}$ is likely to compensate some of the donors and lead to a reduction in free electron density, and most likely a reduction in mobility also due to increased defect scattering.

There is much evidence to suggest that ferromagnetism in transition-metal (TM) doped $\mathrm{ZnO}$ is unambiguously correlated with defects, which depend on the substrate temperature and oxygen pressure used during film deposition; ${ }^{6,52}$ the charge carriers are by products of these defects. Ney et al. ${ }^{53}$ have demonstrated that highly perfect Co-doped epitaxial films, for example, are purely paramagnetic, with cobalt occupying zinc sites and no sign of anything other than weak antiferromagnetic Co-O-Co nearest-neighbor superexchange. Droubay et al. ${ }^{54}$ show that Mn-doped epitaxial films are paramagnetic, with Mn substituting for $\mathrm{Zn}$, and no moments on either oxygen or zinc. Barla et al. ${ }^{55}$ showed that the cobalt in ferromagnetic Co-doped $\mathrm{ZnO}$ films was paramagnetic, and there was no moment on the zinc. A study by Tietze et ll $^{56}$ who investigated 5 at. \% Co-doped films produced by periodic lattice distortion (PLD) which exhibited a moment of $\approx 1 \mu_{\mathrm{B}} /$ $\mathrm{Co}$, corresponding to a magnetization of $\approx 20 \mathrm{kAm}^{-1}$ came to a remarkable conclusion; extensive XMCD ( $\mathrm{x}$-ray magnetic circular dichroism) measurements on the $\mathrm{Co}$ and $\mathrm{O}$ edges with a very good signal/noise ratio showed only the signatures of paramagnetic cobalt and oxygen. There is no sign of elementspecific ferromagnetism. By a process of elimination, only oxygen vacancies remained as the possible intrinsic source of the ferromagnetism observed in the $\mathrm{ZnO}$ films.

Magnetization curves were measured for all samples at $300 \mathrm{~K}$ in the SQUID (superconducting quantum interference device) magnetometer. Data were corrected for the diamagnetic contribution of the $\mathrm{Si}$ substrate, which is determined from the high-field linear part of M-H loops. Fig. 7 shows the room temperature magnetization undoped and $\mathrm{Cu}$ diffusiondoped $\mathrm{ZnO}$ nanorods annealed at $500^{\circ} \mathrm{C}, 600^{\circ} \mathrm{C}$, and $700^{\circ} \mathrm{C}$ for $8 \mathrm{~h}$ in vacuum. It can be noted that all the samples exhibit ferromagnetic behavior at room temperature; however $\mathrm{Cu}$ diffusion-doped $\mathrm{ZnO}$ samples have higher magnetic moment 


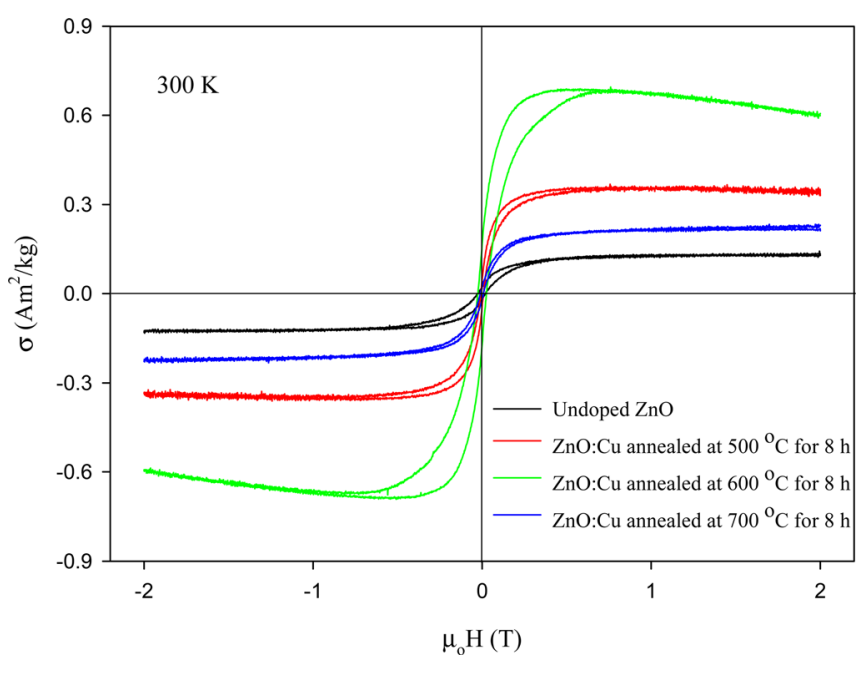

FIG. 7. (Color online) Room temperature $\mathrm{M}-\mathrm{H}$ curves of undoped $\mathrm{ZnO}, \mathrm{Cu}$ diffusion-doped $\mathrm{ZnO}$ nanorods annealed at $500^{\circ} \mathrm{C}, 600^{\circ} \mathrm{C}$, and $700^{\circ} \mathrm{C}$ for $8 \mathrm{~h}$.

values compared to the pure $\mathrm{ZnO}$ one. Similar behaviour was obtained by Kumar et al. ${ }^{57}$ for $\mathrm{Cu}$-doped $\mathrm{ZnO}$ samples. The origin of the ferromagnetism in undoped $\mathrm{ZnO}$ is probably due to defects, based on the previous studies mentioned above, suggesting that the magnetic moment does not originate from $d$ electrons but rather from localized holes in p-bands carrying a magnetic moment. ${ }^{58}$ After annealing the $\mathrm{ZnO}: \mathrm{Cu}$ nanorods at $500{ }^{\circ} \mathrm{C}$ in vacuum, it was found to be the values of saturation magnetization $\left(\mathrm{M}_{\mathrm{s}}\right)$ and coercive field $\left(\mathrm{H}_{\mathrm{c}}\right)$ of $0.19 \mu_{\mathrm{B}} / \mathrm{Cu}$ and $8 \mathrm{mT}$, respectively. When the annealing temperature increases from $500^{\circ} \mathrm{C}$ to $600^{\circ} \mathrm{C}$, the saturation magnetization of the sample is enhanced significantly and reaches a maximum value of $1.39 \mu_{\mathrm{B}} / \mathrm{Cu}$ for the sample annealed at $600^{\circ} \mathrm{C}$. This enhancement may be related to the atomic ratio of $\mathrm{Cu} /$ $\mathrm{Zn}+\mathrm{O}$, determined from the EDS, because for $\mathrm{ZnO}: \mathrm{Cu}$ annealed at $600{ }^{\circ} \mathrm{C}$, this ratio is lower than that of the others and has the value of 0.64 at. \%, which indicates that $\mathrm{Cu}$ solubility in our $\mathrm{ZnO}$ nanorods is below 1 at. \%. ${ }^{59}$ According to the literature, similar trend was observed by Cho et al. ${ }^{60}$ that showed that magnetization of $\mathrm{ZnO}: \mathrm{Cu}$ films increases with increasing $\mathrm{Cu}$ concentration up to 1 at. \% followed by a decrease in ferromagnetic behaviour for $\mathrm{Cu}$ content above 1 at. $\%$. Additionally, Sudakar et al. ${ }^{22}$ found that $\mathrm{ZnO}$ films with $\mathrm{Cu}$ concentration of $\mathrm{x}<1$ at. $\%$ grown by reactive magnetron co-sputtering method on c-cut $\mathrm{Al}_{2} \mathrm{O}_{3}$ substrates exhibited very clear ferromagnetic behavior with a large $\mathrm{M}_{\mathrm{s}}$ value of $1.6 \mu_{\mathrm{B}} / \mathrm{Cu}$, however, for the samples with $\mathrm{x}>1$ at. $\%$, saturation magnetization decreased drastically to $0.4 \mu_{\mathrm{B}} / \mathrm{Cu}$ at 2 at. $\%$ and $0.1 \mu_{\mathrm{B}} / \mathrm{Cu}$ for 6 at. $\% \mathrm{Cu}$ contents. Samanta et al. ${ }^{61}$ also produced $\mathrm{Cu}$-doped $\mathrm{ZnO}$ thin films with the pulsed laser deposition technique on (0001) oriented sapphire substrates and observed a maximum $\mathrm{M}_{\mathrm{s}}$ value of $0.76 \mu_{\mathrm{B}} / \mathrm{Cu}$ for 3 at. $\%$ $\mathrm{Cu}$-doped $\mathrm{ZnO}$ samples at $300 \mathrm{~K}$, however, the saturation magnetization decreased with the further increase of copper concentration. On the other hand, higher annealing temperatures significantly decrease the value of room temperature saturation magnetization and it reaches to $0.31 \mu_{\mathrm{B}} / \mathrm{Cu}$ value. One of the reasons for the decrease in magnetization at high temperature may be attributed to movement and annihilation or complexing of zinc interstitial atoms. The number of $\mathrm{Zn}_{\mathrm{i}}$ defects decreases at high temperature, which in turn could lead to the decrease in saturation magnetization. ${ }^{62}$

It was proposed that oxygen vacancies and zinc interstitials can cause a marked change in the band structure of host semiconductors and make an important contribution to the ferromagnetism. ${ }^{63}$ The formation of bound magnetic polarons (BMPs), which include electrons locally trapped by oxygen vacancy or zinc interstitial, with the trapped electron occupying an orbital overlapping with the d shells of TM neighbors, has also been suggested to explain the origin of ferromagnetism. ${ }^{64}$ In addition to these theoretical studies, several experimental groups have reported that the intrinsic defects play crucial roles in the ferromagnetism of TM-doped $\mathrm{ZnO}$. For example, Hsu et al. ${ }^{65}$ have performed x-ray near edge spectroscopy on Co-doped $\mathrm{ZnO}$ films and shown that the enhancement in ferromagnetism is directly related to an increase in oxygen vacancies. Liu et al. ${ }^{66}$ indicated that point defects such as $\mathrm{Zn}_{\mathrm{i}}$ or $\mathrm{V}_{\mathrm{Zn}}$ are responsible for ferromagnetism in $\mathrm{Cr}: \mathrm{ZnO}$ samples. Furthermore, Liu et al. ${ }^{67}$ suggested that two key factors lead to the appearance of ferromagnetism in TMdoped $\mathrm{ZnO}$ nanocrystals: one is the increase of the number of defects and oxygen vacancies and the other is the exchange interactions between the TM ions and the $\mathrm{O}$ ion spin moment.

The observed ferromagnetism of our $\mathrm{Cu}$ diffusion-doped $\mathrm{ZnO}$ samples could originate from a number of possible sources. Metallic $\mathrm{Cu}$ is diamagnetic and cannot contribute to the observed ferromagnetism. There is no contribution to magnetization from binary copper oxide $\mathrm{CuO}$, which is an antiferromagnetic phase with a Neel temperature of $230 \mathrm{~K}$ (Ref. 68) and diamagnetic cupric oxide $\mathrm{Cu}_{2} \mathrm{O} .{ }^{69}$ In addition, there is no signature metallic $\mathrm{Cu}$ or $\mathrm{CuO}$ related bases in either XRD or XPS measurements. The room temperature ferromagnetism in our $\mathrm{Cu}: \mathrm{ZnO}$ samples is intrinsic and probably results from the magnetic exchange interaction between oxygen vacancies and $\mathrm{Cu}^{2+}$ ions which aligns all the $\mathrm{Cu}^{2+}$ ions around the oxygen vacancies, forming BMPs. ${ }^{70,71}$

\section{CONCLUSIONS}

Based on the structural, optical, and magnetic measurements of our samples the following main points emerge: (1) all the samples exhibit hexagonal structure with a strong (002) preferred orientation normal to the substrate; (2) surface morphology analysis has revealed that the $\mathrm{ZnO}: \mathrm{Cu}$ sample has a well-aligned hexagonal nanorod morphology; (3) XPS results showed the incorporation of $\mathrm{Cu}^{2+}$ into $\mathrm{Zn}$ sites in the $\mathrm{ZnO}$ host lattice; (4) compared to the undoped $\mathrm{ZnO}$, the number of $\mathrm{Cu}$-related optically active deep level defects increased for $\mathrm{Cu}$ diffusion-doped $\mathrm{ZnO}$ nanorod samples; (5) $\mathrm{Cu}$ diffusion-doped $\mathrm{ZnO}$ nanorod samples displayed ferromagnetic loops clearly at room temperature and the origin of the observed room temperature ferromagnetism is probably due to interactions between substitutional $\mathrm{Cu}_{\mathrm{Zn}}$ in a divalent charge with other (intrinsic) point defects, most likely oxygen vacancies, in the crystal.

\section{ACKNOWLEDGMENTS}

The corresponding author (S.Y.) gratefully acknowledges the support of the Council of Turkish Higher 
Education in the form of a fellowship to support extended visits to foreign institutions.

${ }^{1}$ M. S. Arnold, P. Avouris, Z. W. Pan, and Z. L. Wang, J. Phys. Chem. B 107, 659 (2003).

${ }^{2}$ M. H. Huang, S. Mao, H. Feick, H. Yan, Y. Wu, H. Kind, E. Weber, R. Russo, and P. Yang, Science 292, 1897 (2001).

${ }^{3}$ X. Wang, J. Song, J. Liu, and Z. L. Wang, Science 316, 102 (2007).

${ }^{4}$ C. H. Liu, J. A. Zapien, Y. Yao, X. M. Meng, C. S. Lee, S. S. Fan, Y. Lifshitz, and S. T. Lee, Adv. Mater. 15, 838 (2003).

${ }^{5}$ J.-J. Wu, S.-C. Liu, and M.-H. Yang, Appl. Phys. Lett. 90, 062504 (2007).

${ }^{6}$ F. Pan, C. Song, X. J. Liu, Y. C. Yang, and F. Zeng, Mater. Sci. Eng. R 62, 1 (2008).

${ }^{7}$ J. K. Furdyna, J. Appl. Phys. 64, R29 (1988).

${ }^{8}$ S. J. Pearton, W. H. Heo, M. Ivill, D. P. Norton, and T. Steiner, Semicond. Sci. Technol. 19, R59 (2004).

${ }^{9}$ Y. X. Wang, H. Liu, Z. Q. Li, X. X. Zhang, R. K. Zheng, and S. P. Ringer, Appl. Phys. Lett. 89, 042511 (2006).

${ }^{10}$ T. Dietl, H. Ohno, F. Matsukura, J. Cibert, and D. Ferrand, Science 287, 1019 (2000).

${ }^{11}$ K. Sato and H. Katayama-Yoshida, Jpn. J. Appl. Phys., Part 2 39, L555 (2000).

${ }^{12}$ K. Ueda, H. Tabata, and T. Kawai, Appl. Phys. Lett. 79, 988 (2001).

${ }^{13}$ Z. Jin, T. Fukumura, M. Kawasaki, K. Ando, H. Saito, T. Sekiguchi, Y. Z. Yoo, M. Murakami, Y. Matsumoto, T. Hasegawa, and H. Koinuma, Appl. Phys. Lett. 78, 3824 (2001).

${ }^{14}$ J. M. D. Coey, A. P. Douvalis, C. B. Fitzgerald, and M. Venkatesan, Appl. Phys. Lett. 84, 1332 (2004).

${ }^{15}$ G. Z. Xing, J. B. Yi, J. G. Tao, T. Liu, L. M. Wong, Z. Zhang, G. P. Li, S. J. Wang, J. Ding, T. C. Sum, C. H. A. Huan, and T. Wu, Adv. Mater. 20, 3521 (2008).

${ }^{16}$ A. Wang, B. Zhang, X. Wang, N. Yao, Z. Gao, Y. Ma, L. Zhang, and H. Ma, J. Phys. D: Appl. Phys. 41, 215308 (2008).

${ }^{17}$ T.-L. Phan, S. C. Yu, R. Vincent, H. M. Bui, T. D. Thanh, V. D. Lam, and Y. P. Lee, J. Appl. Phys. 108, 044910 (2010).

${ }^{18}$ D. B. Buchholz, R. P. H. Chang, J. H. Song, and J. B. Ketterson, Appl. Phys. Lett. 87, 082504 (2005).

${ }^{19}$ L. H. Ye, A. J. Freeman, and B. Delley, Phys. Rev. B 73, 33203 (2006).

${ }^{20}$ L. M. Huang, A. L. Rosa, and R. Ahuja, Phys. Rev. B 74, 75206 (2006).

${ }^{21}$ D. Chakraborti, J. Narayan, and J. T. Prater, Appl. Phys. Lett. 90, 062504 (2007).

${ }^{22}$ C. Sudakar, J. S. Thakur, G. Lawes, R. Naik, and V. M. Naik, Phys. Rev. B 75, 054423 (2007).

${ }^{23}$ Q. Y. Xu, H. Schmidt, S. Q. Zhou, K. Potzger, M. Helm, H. Hochmuth, M. Lorenz, A. Setzer, P. Esquinazi, C. Meinecke, and M. Grundmann, Appl. Phys. Lett. 92, 082508 (2008)

${ }^{24}$ T. S. Herng, S. P. Lau, S. F. Yu, H. Y. Yang, L. Wang, M. Tanemura, and J. S. Chen, Appl. Phys. Lett. 90, 032509 (2007).

${ }^{25}$ J. J. Liu, M. H. Yu, and W. L. Zhou, J. Appl. Phys. 99, 08M119 (2006).

${ }^{26}$ Y. Zuo, S. Ge, Z. Chen, L. Zhang, X. Zhou, and S. Yan, J. Alloy Compd. 470, 47 (2009).

${ }^{27}$ K.-H. Zheng, Z. Liu, J. Liu, L.-J. Hu, D.-W. Wang, C.-Y. Chen, and L.-F. Sun, Chin. Phys. B 19, 026101 (2010).

${ }^{28}$ L.W. Yang, W. L. Wu, T. Qiu, G. G. Siu, and P. K. Chu, J. Appl. Phys. 99, 074303 (2006).

${ }^{29}$ Y. Q. Chang, D. B. Wang, X. H. Luo, X. Y. Xu, X. H. Chen, L. Li, C. P. Chen, R. M. Wang, J. Xu, and D. P. Yu, Appl. Phys. Lett. 83, 4020 (2003).

${ }^{30}$ C. X. Xu, X. W. Sun, and B. J. Chen, Appl. Phys. Lett. 84, 1540 (2004).

${ }^{31}$ M. Biswas, E. McGlynn, M. O. Henry, M. McCann, and A. Rafferty, J. Appl. Phys. 105, 094306 (2009).

${ }^{32}$ D. Byrne, E. McGlynn, K. Kumar, M. Biswas, M. O. Henry, and G. Hughes, Cryst. Growth Des. 10, 2400 (2010).

${ }^{33}$ L. E. Greene, M. Law, D. H. Tan, M. Montano, J. Goldberger, G. Somorjai, and P. Yang, Nano Lett. 5, 1231 (2005).

${ }^{34}$ L. L. Yang, Q. X. Zhao, and M. Willander, J. Alloy Compd. 469, 623 (2009).

${ }^{35}$ Ü. Özgür, Y. I. Alivov, C. Liu, A. Teke, M. A. Reshchikov, S. Doğan, V. Avrutin, S.-J. Cho, and H. Morkoç, J. Appl. Phys. 98, 041301 (2005).

${ }^{36}$ B.-H. Hwang, J. Phys. D: Appl. Phys. 34, 2469 (2001).

${ }^{37}$ X. B. Wang, C. Song, K. W. Geng, F. Zeng, and F. Pan, Appl. Surf. Sci. 253, 6905 (2007).
${ }^{38}$ L. Yanmei, W. Tao, S. Xia, F. Qingqing, L. Qingrong, S. Xueping, and S. Zaoqi, Appl. Surf. Sci. 257, 6540 (2011).

${ }^{39}$ E. McCarthy, R. T. R. Kumar, B. Doggett, S. Chakrabarti, R. J. O'Haire, S. B. Newcomb, J.-P. Mosnier, M. O. Henry, and E. McGlynn, J. Phys. D: Appl. Phys. 44, 375401 (2011).

${ }^{40}$ Y. Y. Peter and M. Cardona, Fundamentals of Semiconductors: Physics and Material Properties (Springer, Berlin, 2001).

${ }^{41}$ X. Wang, J. B. Xu, W. Y. Cheung, J. An, and N. Ke, Appl. Phys. Lett. 90, 212502 (2007).

${ }^{42}$ D. Chakraborti, G. R. Trichy, J. T. Prater, and J. Narayan, J. Phys. D: Appl. Phys. 40, 7606 (2007)

${ }^{43}$ J.-B. Lee, H.-J. Lee, S.-H. Seo, and J.-S. Park, Thin Solid Films 398, 641 (2001).

${ }^{44}$ J. Qi, D. Gao, L. Zhang, and Y. Yang, Appl. Surf. Sci. 256, 2507 (2010).

${ }^{45}$ B. K. Meyer, H. Alves, D. M. Hofmann, W. Kriegseis, D. Forster, F. Bertram, J. Christen, A. Hoffmann, M. Straßburg, M. Dworzak, U. Haboeck, and A. V. Rodina, Phys. Status Solidi B 241, 231 (2004).

${ }^{46}$ Ü. Özgür, Y. I. Alivov, C. Liu, A. Teke, M. A. Reshchikov, S. Dogan, V. Avrutin, S. J. Cho, and H. Morkoc, J. Appl. Phys. 98, 041301 (2005).

${ }^{47}$ D. C. Look, G. C. Farlow, P. Reunchan, S. Limpijumnong, S. B. Zhang, and K. Nordlund, Phys. Rev. Lett. 95, 225502 (2005).

${ }^{48}$ Y. Liu, H. Liang, L. Xu, J. Zhao, J. Bian, Y. Luo,Y. Liu, W. Li, G. Wu, and G. Du, J. Appl. Phys. 108, 113507 (2010).

${ }^{49}$ R. Dingle, Phys. Rev. Lett. 23, 579 (1969).

${ }^{50}$ H. J. Xu, H. C. Zhu, X. D. Shan, Y. X. Liu, J. Y. Gao, X. Z. Zhang, J. M. Zhang, P. W. Wang, Y. M. Hou, and D. P. Yu, J. Phys.: Condens. Matter 22, 016002 (2010).

${ }^{51}$ J. Goldberger, D. J. Sirbuly, M. Law, and P. Yang, J. Phys. Chem. B 109, 9 (2005).

${ }^{52}$ K. Potzger and S. Zhou, Phys. Status Solidi B 246, 1147 (2009).

${ }^{53}$ A. Ney, K. Ollefs, S. Ye, T. Kammermeier, V. Ney, T. C. Kaspar, S. A. Chambers, F. Wilhelm, and A. Rogalev, Phys. Rev. Lett. 100, 157201 (2008).

${ }^{54}$ T. C. Droubay, D. J. Keavney, T. C. Kaspar, S. M. Heald, C. M. Wang, C. A. Johnson, K. M. Whitaker, D. R. Gamelin, and S. A. Chambers, Phys. Rev. B 79, 155203 (2009).

${ }^{55}$ A. Barla, G. Schmerber, E. Beaurepaire, A. Dinia, H. Bieber, S. Colis, F. Scheurer, J.-P. Kappler, P. Imperia, F. Nolting, F. Wilhelm, A. Rogalev, D. Müller, and J. J. Grob, Phys. Rev. B 76, 125201 (2007).

${ }^{56}$ T. Tietze, M. Gacic, G. Schütz, G. Jakob, S. Brück, and E. Goering, New J. Phys. 10, 055009 (2008).

${ }^{57}$ S. Kumar, B. H. Koo, C. G. Lee, S. Gautam, K. H. Chae, S. K. Sharma, and M. Knobel, Funct. Mater. Lett. 4, 17 (2011).

${ }^{58}$ J. M. D. Coey, Solid State Sci. 7, 660 (2005).

${ }^{59}$ M. S. Park and B. I. Min, Phys. Rev. B 68, 224436 (2003).

${ }^{60}$ C.-R. Cho, J.-Y. Hwang, J.-P. Kim, S.-Y. Jeong, M.-S. Jang, W.-J. Lee, and D.-H. Kim, Jpn. J. Appl. Phys. 43, L1383 (2004).

${ }^{61}$ K. Samanta, P. Bhattacharya, and R. S. Katiyar, J. Appl. Phys. 105, 113929 (2009).

${ }^{62}$ M. H. F. Sluiter, Y. Kawazoe, P. Sharma, A. Inoue, A. R. Raju, C. Rout, and U. V. Waghmare, Phys. Rev. Lett. 94, 187204 (2005).

${ }^{63}$ L. W. Guo, D. L. Peng, H. Makino, K. Inaba, H. J. Ko, K. Sumiyama, and T. Yao, J. Magn. Magn. Mater. 213, 321 (2000).

${ }^{64}$ J. M. D. Coey, M. Venkatesan, and C. B. Fitzgerald, Nature Mater. 4, 173 (2005).

${ }^{65}$ H. S. Hsu, J. C. A. Huang, Y. H. Huang, Y. F. Liao, M. Z. Lin, C. H. Lee, J. F. Lee, S. F. Chen, L. Y. Lai, and C. P. Liu, Appl. Phys. Lett. 88, 242507 (2006).

${ }^{66}$ H. Liu, X. Zhang, L. Li, Y. X. Wang, K. H. Gao, Z. Q. Li, R. K. Zheng, S. P. Ringer, B. Zhang, and X. X. Zhang, Appl. Phys. Lett. 91, 072511 (2007).

${ }^{67}$ Y. Liu, J. Yang, Q. Guan, L. Yang, Y. Zhang, Y. Wang, B. Feng, J. Cao, X. Liu, Y. Yang, and M. Wei, J. Alloy. Compd. 486, 835 (2009).

${ }^{68}$ V. B. Kopylov and E. V. Sergeev, Russ. J. Gen. Chem. 78, 1111 (2008).

${ }^{69}$ M. Wei, N. Braddon, D. Zhi, P. A. Midgley, S. K. Chen, M. G. Blamire, and J. L. MacManus-Driscoll, Appl. Phys. Lett. 86, 72514 (2005).

${ }^{70}$ G. Weyer, H. P. Gunnlaugsson, R. Mantovan, M. Fanciulli, D. Naidoo, K. Bharuth-Ram, and T. Agne, J. Appl. Phys. 102, 113915 (2007).

${ }^{71}$ S. Yılmaz, M. Parlak, Ş. Özcan, M. Altunbaş, E. McGlynn, and E. Bacaksı, Appl. Surf. Sci. 257, 9293 (2011). 